\title{
Effect of response task on taste adaptation
}

\author{
HERBERT L. MEISELMAN \\ Food Sciences Laboratory, U.S. Army Natick Laboratories, Natick, Massachusetts 01760
}

\begin{abstract}
Two experiments studied whether subjects reported complete adaptation of a taste sensation. Three tasks were chosen based on their use in other laboratories: hand lowering to connote stimulus absence, magnitude estimation, and cross-adaptation of a brief stimulus following a prolonged stimulus. In the first experiment, different groups of 9 subjects received the three different tasks; in the second experiment, all 20 subjects received all three tasks. In both experiments, subjects failed to demonstrate complete taste adaptation in at least $50 \%$ of adaptation trials. Response task did affect the likelihood of observing complete taste adaptation.
\end{abstract}

Many recent basic references in psychology (Bartoshuk, 1971), chemical senses (Pfaffman, McBurney, \& Bartoshuk, 1971), and food science (Amerine, Pangborn, \& Roessler, 1965) state that taste stimuli of moderate intensity adapt completely when the stimulus is presented continuously. Failure of subjects to adapt to a continuous taste stimulus is attributed to insufficient time of exposure to the stimulus or tactile components of the stimulus (Bartoshuk, 1968), lack of stimulus constancy (Abrahams, Krakauer, \& Dallenbach, 1937; Meiselman, 1968), or tongue movements (Krakauer \& Dallenbach, 1937; Meiselman, 1968). Most studies that use taste adaptation as a research tool or which study taste adaptation directly have not reported specific data on whether all subjects showed complete adaptation. Meiselman (1972) reported that subjects differ widely in their tendency to report complete adaptation, and that different stimulus presentation methods may affect the probability of observing complete adaptation.

Lack of standardized techniques in human gustatory research (Meiselman, 1972) has resulted in a variety of procedures used to attempt to produce taste adaptation and in a variety of tasks with which to measure it. Adaptation has been attempted with stimuli simply sipped and held in the mouth, with the resulting dilution by saliva (Meiselman, 1968), and sipped repeatedly to avoid progressive dilution by saliva (Meiselman. 1968). In addition, a variety of techniques have been used which use a continuously flowing stimulus. One of the early flowing devices was the Cornell gustometer (Abraham, Krakauer, \& Dallenbach, 1937), which stimulated the entire mouth. This has recently been modified by Meiselman (1971). A different approach to flowing stimuli has been the anterior dorsal tongue flow widely used by a variety of investigators and laboratories in recent years.

The course of gustatory adaptation has been measured with a variety of techniques. The classical approach (Hahn, 1934) was through the measurement of the taste threshold, and this approach is still used in taste adaptation research (McBurney, Kasschau, \& Bogart, 1967). The simplest task has been the use of a signal from the subject (e.g.. hand raising) to signal when the taste of the flowing stimulus has disappeared, indicating adaptation (Abrahams et al., 1937; Krakauer \& Dallenbach, 1937). Taste adaptation has been widely used in gustatory research through the procedure of cross-adaptation, in which the experimenter presents a lengthy exposure to one stimulus followed immediately by a brief exposure to a second stimulus. If the adaptation to the first stimulus decreases or abolishes the perception of the second stimulus, then the two stimuli are assumed to have similar characteristics (McBurney, 1969; Meiselman, 1972). The duration of the first, longer stimulus is usually arbitrarily assigned, i.e., it is not dependent on the disappearance of the taste of the flowing stimulus. The brief second stimulus is usually described in qualitative and quantitative terms. The quality response indicates cross-adaptation because it should disappear or change with complete adaptation (McBurney \& Bartoshuk, 1973; McBurney \& Shick, 1971). The intensity of this taste produced by cross-adaptation is usually measured with a ratio scaling technique, called magnitude estimation, in which stimulus strength is described relative to an arbitrary standard. Stimuli twice as strong as the standard are assigned numbers twice as large, and so on. In the present experiment, the effect of exposure to a compound on itself is used as a measure of adaptation. Direct magnitude estimation of the course of gustatory adaptation has been used (Meiselman. 1968), although complete adaptation has rarely been observed.

The present experiments were undertaken to study directly whether a taste sensation completely adapts, i.e., whether a number of various reporting tasks indicate absence of stimulus perception. Three tasks were chosen based on their use in other laboratories; a 
Hand raIss Ermogra I:

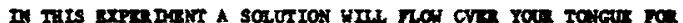

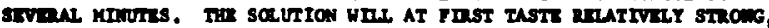

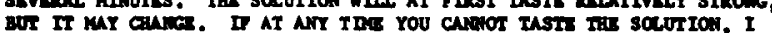

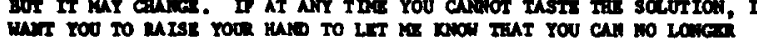

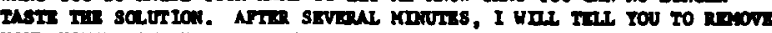

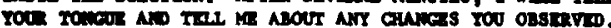

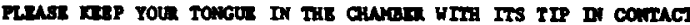

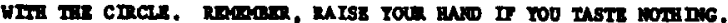

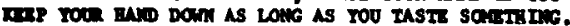

\section{Metrobe estDation I:}

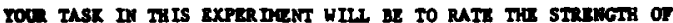

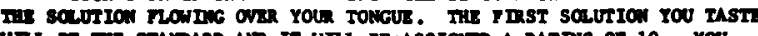

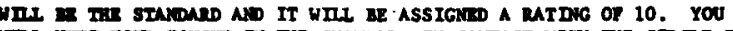

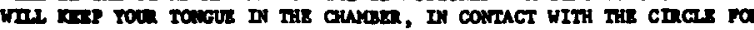

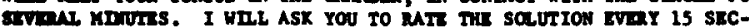

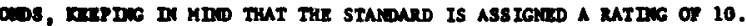

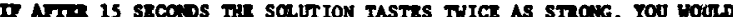
UTI IT AS 20. I IT TASTES $1 / 2$ AS SIRONG, YOU woUt RATB IT AS A A. $80 \mathrm{ch}$.

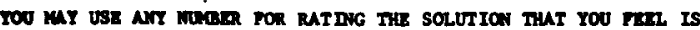

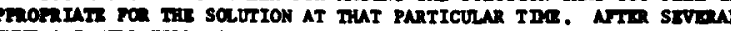

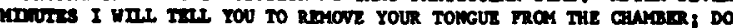
wor Rever IT ving Tow to do so:

\section{Gross abaptation I,}

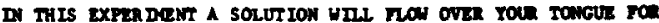

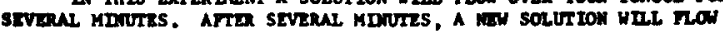

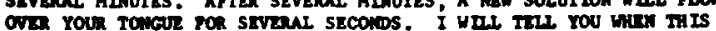

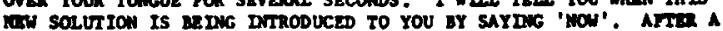

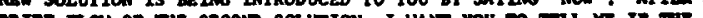

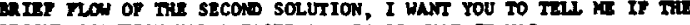
SECOND SOLUTION HAD A IASTE ANI IF SO WHT IT WAS.

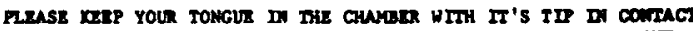

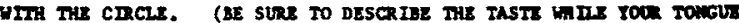
IS STIIL IN The GWRer).

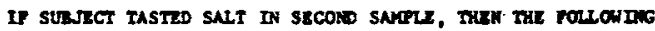
comrtrons APPLY

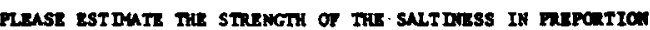

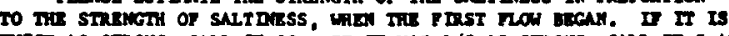
INICE AS STRONG, CALI IT 20. IF IT WAS $1 / 2$ AS STRCNG, CALL IT 5 ANO

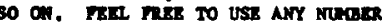

Figure 1. Instructions for Experiment I.

hand-raise task in which absence of the stimulus is defined by hand-lowering, a magnitude estimation task in which numbers are assigned to perceived stimulus strengths and hence complete adaptation is zero, and a cross-adaptation task in which the salty quality of a brief exposure to salt after prolonged exposure to salt should be missing. Two experiments are ported; in the first, different groups of subjects received the three different tasks, while in the second, all subjects received all tasks.

\section{EXPERIMENT I}

\section{Method}

Subjects. The subjects were 27 enlisted males at U.S. Army Natick Laboratories between 18 and 23 years of age. The subjects were part of the Army's military test subjects program, and they volunteered for the test. The subjects did not know the purpose of the experiment. nor were they tamiliar with taste judgments. Nine different subjects received each of three adaptation procedures.

Stimulus. The one stimulus solution for the experiment was $360 \mathrm{mM} \mathrm{NaCl}$ prepared with distilled water $(\mathrm{r} / \mathrm{f}=1.3330)$ and reagent grade $\mathrm{NaCl}$. The solution was kept in a water bath at $34^{\circ} \mathrm{C}$.

Procedure. The $360 \mathrm{mM} \mathrm{NaCl}$ stimulus was located in two polypropylene bottles (one 5-gal type and the other 1 gal) sitting in a water bath. The bottles were pressurized at 5 psi to deliver the stimulus through plastic tubing to the subjects at $5 \mathrm{ml} / \mathrm{sec}$. The delivery of the solution for the magnitude estimation and hand-raise experiments was a continuous flow, for $3 \mathrm{~min}$, from the larger bottle. For the cross-adaptation experiment, there was a 3 -min flow to the subject from the large bottle, followed by a $5-\mathrm{sec}$ flow from the small bottle. This was accomplished through the use of a two-way stopcock.

The subject was seated in front of the water bath. The procedure for the three different tasks was as follows: The subject was asked to place his tongue in a tongue-fixation chamber which consisted of two parallel Plexiglas bars with a tongue fixation point on which the subject was instructed to touch the tip of his tongue (Meiselman. 1972: Meiselman \& Halpern, 1973). For all presentations, the subject was asked to extend his tongue and the liquid was flowed over the anterior dorsal surface (McBurney, 1966; Meiselman, 1971). Instructions for this experiment are shown in Figure 1. The subjects recorded their own data for magnitude estimation; data for each 3-min adaptation were removed as soon as completed.

\section{Results}

Median magnitude estimations were calculated for the three replications for nine subjects, and are presented in Figure 2. The adaptation function begins at the assigned value of 10 and ends at 3.0 at the end of 3 min. The low points of the adaptation curve was reached at $150 \mathrm{msec}(3.0)$. Calculations based on the arithmetic mean show no significant differences in the last several data points. Two subjects did report zero magnitude (i.e. complete adaptation) on each of their three replications for a total of six adaptations in 27 presentations. One of the two subjects adapted to zero and remained there, while the other subject adapted to zero three times and then reported a positive magnitude estimate for the last two reports. Reports above the starting value of 10 were common. Twelve out of 27 individual functions exceed 10 at at least one point. One subject consistently stayed at or above 10 for all three replications.

With the hand-raise procedure, 21 out of 27 replications indicated that complete adaptation was reached at least once (Figure 3). Four different subjects did not reach complete adaptation at least once in three replications; one subject never reached complete adaptation. Six subjects reached adaptation

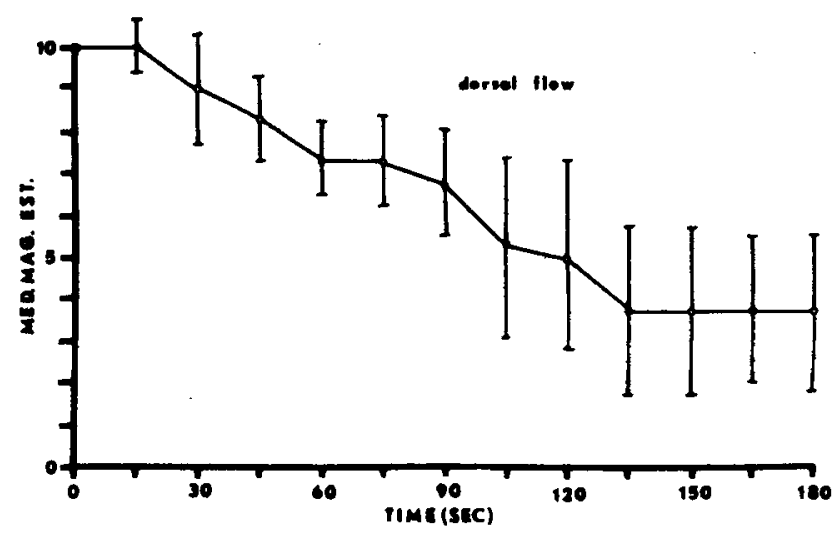

Figure 2. Median magnitude estimations for nine subjects for three replications (each data point is based on 27 measures). 
more than one time in a $3-\mathrm{min}$ procedure, that is, they reported adaptation, then reported a nonadapted state, and then reported a return to an adapted state. Out of 27 replications, the numbers per 3-min procedure were as follows: (a) no adaptations, 6; (b) one adaptation, 9; (c) two adaptations, 6; (d) three adaptations, 3; (e) four adaptations, 2; and (f) tive adaptations, 1 . The earliest adaptation out of the 27 was at $15 \mathrm{sec}$.

In the cross-adaptation procedure, no temporal data are available, only the qualitative reports of the cross-adapted stimulus. Out of 27 reports, salty (indicating incomplete adaptation) was given 16 times, sweet 4 times, and no taste (indicating complete adaptation) 7 times. The median magnitude estimation assigned the salty quality was 8 . Data on the small number of sweet reports are incomplete. Interestingly, five subjects reported salty on each of three trials and three subjects never reported salty; one subject reported sweet on each of three replications, and one subject reported no taste on each of the three replications. Two other subjects each reported two no-taste responses out of three.

The results of Experiment $I$ are summarized in Table1.

\section{EXPERIMENT II}

\section{Method}

Subjects. The subjects were 20 lab technicians at U.S. Army Natick Laboratories, between 21 and 28 years of age. The subjects were familiar with taste judgment, but they did not know the purpose of the experiment. All of the 20 subjects received the three adaptation procedures.

Stimulus. The one taste stimulus solution for the experiment, $360 \mathrm{mM} \mathrm{NaCl}$, was prepared with distailled water and reagent grade $\mathrm{NaCl}$. The solution was kept in a water bath at $34^{\circ} \mathrm{C}$.

Procedure. The $360 \mathrm{mM}$ stimulus was located in two polypropylene bottles set in a water bath. There was also a bottle of distilled water in the bath that was used as a rinse.

The bottles were pressured at 5 psi to deliver the stimulus to the subject at $5 \mathrm{ml} / \mathrm{sec}$. In the hand-raise and magnitude estimation

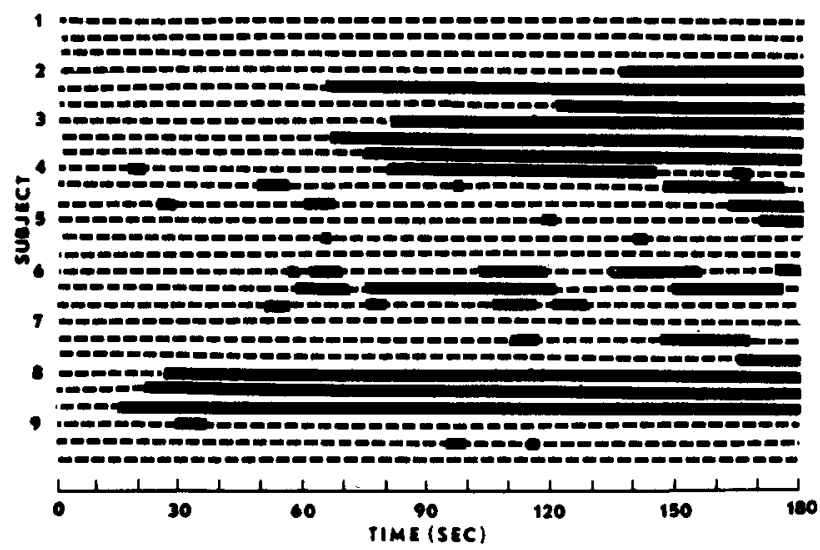

Figure 3. Complete adaptations indicated by hand raising. The hatched line indicates the hand was lowered, showing presence of sensation. The heavy solid line indicates the hand was raised, showing absence of sensation.
Table 1

Experiment I

\begin{tabular}{lccc}
\hline & $\begin{array}{c}\text { Number of } \\
\text { Complete } \\
\text { Adaptations } \\
\text { in 27 } \\
\text { Trials } \\
(\mathrm{N}=27)\end{array}$ & $\begin{array}{c}\text { Number of Subjects } \\
\text { Reaching } \\
\text { Complete } \\
\text { Adaptation } \\
\text { Every Time } \\
(\mathrm{N}=9)\end{array}$ & $\begin{array}{c}\text { Ever } \\
\text { Reaching } \\
\text { Complete } \\
\text { Adaptation } \\
(\mathrm{N}=9)\end{array}$ \\
\hline $\begin{array}{l}\text { Magnitude } \\
\text { Estimation }\end{array}$ & 6 & 2 & 2 \\
$\begin{array}{l}\text { Hand Raise } \\
\text { Cross }\end{array}$ & 21 & 4 & 8 \\
Adaptation & 7 & 1 & 3 \\
\hline
\end{tabular}

experiment, the flow was continuous for $3 \mathrm{~min}$. In the cross-adaptation experiment, the $\mathrm{NaCl}$ flowed for $3 \mathrm{~min}$ from one bottle, and then an electric wave was used to change the source of an identical $\mathrm{NaCl}$ solution for $15 \mathrm{sec}$. Instructions for the second experiment are shown in Figure 4. The subjects recorded their own data for magnitude estimation; data for each 3-min adaptation were removed as soon as completed.

\section{Results}

Median magnitude estimations were calculated for each trial for the 20 subjects, and are presented in Figure 5. The adaptation function begins at the assigned value of 10 , decreases to 5 at $1 \mathrm{~min}$, and remains at a value of 5-6.5 until $180 \mathrm{sec}$, when there is a jump to 8 . Out of the 20 subjects, 3 reported zero magnitude (Table 2 ), although only 1 stayed adapted after reaching the zero level $($ at $90 \mathrm{sec})$. The other two either returned to the initial value of 10 or varied between ratings of 5 and 10 . Twelve out of 20 subjects reported a magnitude greater than 10 at some point during their 180 -sec procedure. One subject reported no change in intensity (i.e., a rating of 10 ) throughout the $180 \mathrm{sec}$, and another stayed at a rating of 10 or above for that time.

With the hand-raise procedure, 8 of 20 subjects showed complete adaptation at least once, and therefore, 12 subjects never indicated adaptation by raising their hands. Five subjects gave more than one hand raise in $180 \mathrm{sec}$. The numbers of adaptations per 180-sec procedure were as follows: (a) no adaptations, 12; (b) one adaptation, 3; (c) two adaptations, 1; (d) three adaptations, 1; (e) four adaptations, 2; and ( $f$ ) five adaptations, 1 (Figure 6). In the hand-raise procedure, the earliest adaptation reported was at $29 \mathrm{sec}$.

In the cross-adaptation procedure, out of 20 subjects, 6 reported salty, 4 reported sweet, 1 reported sour, and 9 reported no taste, indicating complete adaptation. The median magnitude estimations assigned the salty and sweet qualities were 6 and 4, respectively. Out of the 6 subjects who did report salty taste in a cross-adaptation situation, 5 never showed adaptation with any of the three procedures.

The results of Experiment II are summarized in Table 2. 
WND RAISE II:

II THIS EXPER DEET A SOLUTION (MCL) WTI FLOW OVER YOUR TONGU:

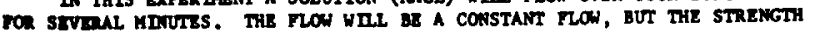
Or TRIS SOLUTION MY GHNGE.

YOU IASX WIIL BR TO OASERV THESE GANGS AND RBLATE THEY TO HE ATES THE TON BAS STORPD. INIT LLLY THE STRENGT OF THE SOLUTION WIII AS ASTGINO A RATING OF 10 . IF THE SOLUTION BECOMS TWICE AS STRONG If woud gave A valus or 20 .

LDOWISE IT THE SOLUTION BEcontes $1 / 2$ AS STRONG IT WOULD BE ASSIGNED A RATIic of $\underline{5}$. AND SO OA $(1 / 10=\underline{1}, 5 X=\underline{50})$.

ArY QUEsTIONS.

IF AT ANY TDE YOU CANMOT TASTE THE MCL (THE SOLUTION TASTES LIKE H20) I WANT YOU TO MAISE YOUR HAND TO INDICATE THIS TO RE. CONTINUS TO HOW YOUR HANO UP AS LONG AS YOU CAN NOT TASTE THE MACL.

AT THE END OF SEVEAL MINUTES, I WRI STOP THE now AND IP YOU CAN TAST DIE MCL AT TAIS TDE, HOW WOUD YOU RATI IT ACCORDING TO THE DIILL scouriow waIca us ASSIGNSD A VALUE or 10 .

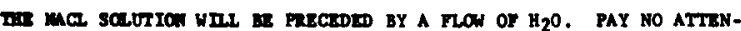
ina to mereoun now of the socution.

\section{Coss snururion II:}

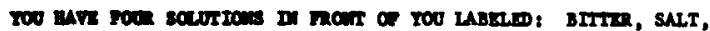

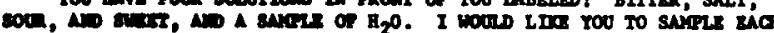

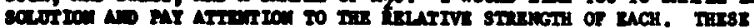

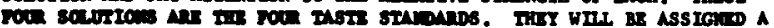
varus a 10.

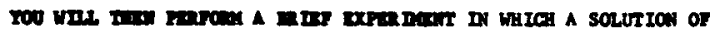

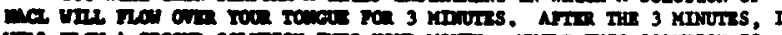

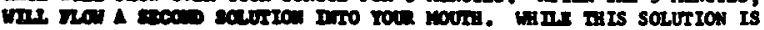

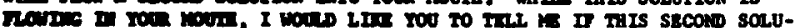

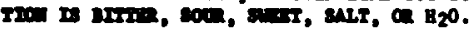

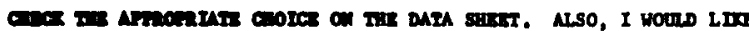

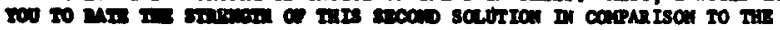

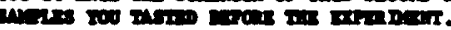

$\sin 10$ at $=10$

$1 / 2-5$

$2 x-2$ ate.

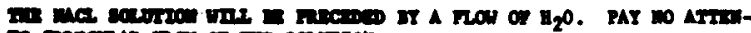

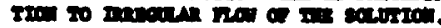

MenITUDE IST IATIOA II:

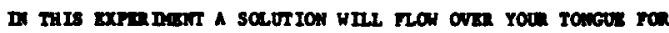

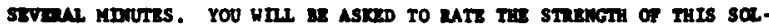

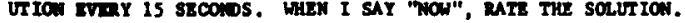

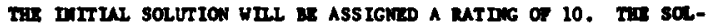

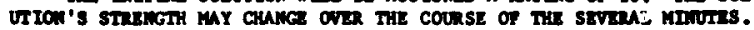

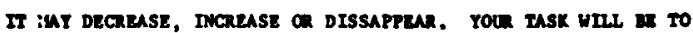

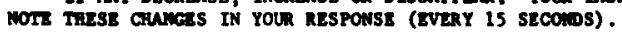

IF THE SOLUTION BECORES TWICE AS STRONG, CALL IT 20 . IT IT IS $1 / 2$ AS STRONG, CALL IT 5, etc. If IT HAS NO TASTE, CALL IT 0, ete.

FEEL FRE TO ASX ANY QUESTIONS.

TAE MACL SOLUTION WLL BE PRECEDED DY A FLON OF H $\mathrm{H}_{2} \mathrm{O}$. PAY MO ATHMTION TO ANY IRREGULAR ROW OF THE SOLUTION.

Figure 4. Instructions for Experiment II.

\section{DISCUSSION}

These data demonstrate that taste does not adapt completely for a salty stimulus of moderate strength with a variety of response tasks. Taken together with the data which demonstrate that individual subjects differ greatly in the likelihood of reading complete adaptation in $2 \mathrm{~min}$ for salt and that different stimulus presentation procedures affect the proba-

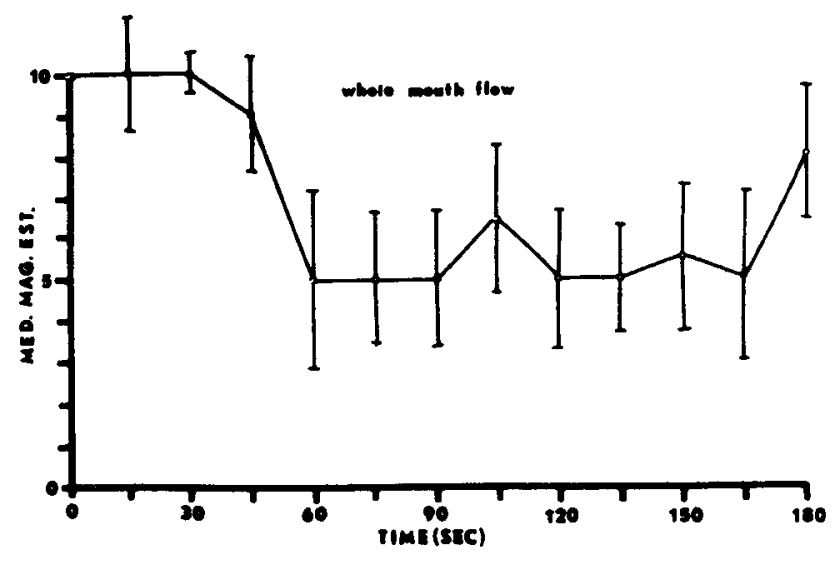

Figure 5. Median magnitude estimations for 20 subjects.

bility of observing complete adaptation (Meiselman, 1972), all of these data question the generality of complete adaptation in gustation.

It should be noted immediately that it is not being argued that complete adaptation in taste is inpossible. In every procedure, in every response task, some subjects report that the stimulus disappears. In Meiselman's (1972) data on 80 adaptation sessions. functions for each of tive subjects indicated that one subject (out of five) would probably show adaptation to salt or quinine nearly $70 \%$ of the time, two subjects would show adaptation to salt about $25 \%$ of the time, and the remaining subjects (two for salt, four for quinine) would rarely show complete adaptation. Only one subject in five regularly adapted on more than $50 \%$ of the replications. When the same data were reorganized by stimulus presentation procedure, the anterior dorsal tongue flow method was shown to increase the likelihood of observing complete adaptation with many salt and quinine concentrations. Both sipping methods and whole-mouth irrigation appeared more sensitive to concentration, yielding more complete adaptations at lower concentrations. No method regularly yielded greater than $50 \%$ complete adaptation.

In the present experiments, only the hand-raise task approaches $50 \%$ adaptation rate (i.e., complete adaptation reported on half the trials). With magnitude estimation, the percentage showing complete adaptation is considerably lower (nearer

Table 2

Experiment II

Number of Subjects

Out of 20 Showing

Complete Adaptation

Magnitude Estimation 3

Hand Raise

8

Cross Adaptation 


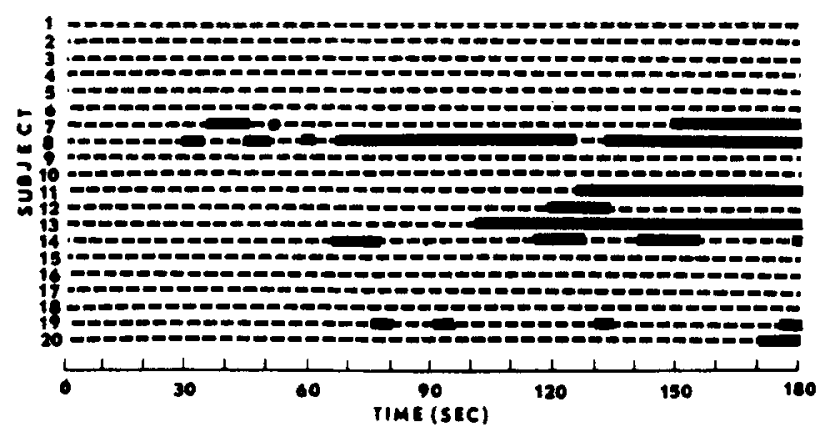

Figure 6. Complete adaptations indicated by hand raising. The hatched line indicates the hand was lowered, showing presence of sensation. The heavy solid line indicates the hand was raised, showing absence of sensation.

$20 \%$ ), and for the cross-adaptation task, it appears more variable, but always below $50 \%$. Thus, the overall conclusions remain that unbiased selection of subjects, stimulus presentation procedures, and response tasks do not yeld more than $50 \%$ occurrence of complete adaptation.

These data suggest that other variables in the taste adaptation situation be investigated before any final estimate is reached as to the percentage of adapters in the population, i.e., subjects likely to report complete adaptation of a taste sensation. One possible variable to consider is the demand characteristics of the instructions. The present instructions are neutral with respect to the completeness of adaptation. It is possible that other investigators have used instructions with varying degrees of neutrality. Most puhlished reports have not contained the specific instructions used or any indication as to whether all subjects received identical instructions.

\section{REFERENCES}

Abrahams, H., Krakauer, D., \& Dallenbach, K. M. Gustatory adaptation to salt. American Journal of Psychology, 1937, 49. $462-469$.

amerine, M. A.. Pangborn, R. M.. \& Roessler, E. B. Principles of sensory evaluation of food. New York: Academic Press. 1965 .
Principles of sensory evaluation of food. New York: Academic Press. 1965.

Bartushuk, L. Water taste in man. Perception \& Psychophysics, 1968, 3, 69-72.

Bartoshuk, L. The chemical senses, I. Taste. In J. Kling and L. Riggs (Eds.). Woodn'ard and Schlossberg's Experimental psychology, (3rd ed.). New York: Holt, Rinehart, and Winston, 1971. Pp. 169-192.

HAHN, H. Die Adaptation des Geschmachsinnes. Zinnes Sinnesphysiologie, 1934, 65, 104-145.

Krakauer, D., \& Dallenbach, K. M. Gustatory adaptation to sweet, sour, and bitter. American Joumal of Psychology. $1937,49,469-475$.

McBurney, D. H. Magnitude estimation of the taste of sodium chloride after adaptation to sodium chloride. Journal of Experimental Psychology, 1966, 72, 869-873.

MCBURney, D. H. Effects of adaptation on human taste function. In C. Pfaffmann (Ed.). Olfaction andtaste III. New York: Rockefeller University Press, 1969.

MCBurney, D. H., \& Bartoshux, L. M. Interactions between stimuli with different taste qualities. Physiology and Behavior, $1973,10,1101-1106$.

McBurney, D. H., Kasschau, R. A.. \& Bogart, L. M. The effect of adaptation on taste jnds. Perception \& Psychophysics, 1967, 2. 175-178.

MCBurney, D. H., \& Shick, T. R. Taste and water taste on twenty-six compounds for man. Perception \& Psychophysics, $1971,10,249-252$.

Meiselman. H. L. Magnitude estimations of the course of gustatory adaptation. Perception \& Psychophusics, 1968, 4, 193-196.

Meiselman, H. L. Effect of presentation procedure on taste intensity functions. Perception \& Psychophysics, 1971, 10, 15-18.

Meiselman, H. L. Human taste perception. Chemical Rubber Company Reviews in Food Technology, 1972, 89.119.

Meiselman, H. L., \& Halpern, B. P. Enhancement of taste intensity through pulsatile stinulation. Physiology and Behavior, 1973, 11, 713-716.

Pfaffmann, C. M., McBurney, D. H., \& Bartoshuk, L. M. Taste psychophysics. In L. Biedler (Ed.), Handbook of physiology. Berlin: Springer-Verlag, 1971.
(Received for publication December 17, 1974; revision accepted March 16, 1975.) 